\title{
Robust Fuzzy Sliding Mode Observer for Faults Detection in Solar Power Plant Application
}

\author{
Taif Zahra*, Lafifi M. Mourad, Abbassi Haj Ahmed
}

Laboratory of Automatic and Signals, Annaba (LASA), Department of Electronics, Badji Mokhtar University, Annaba 23000, Algeria

Corresponding Author Email: zahraautomatique@gmail.com

https://doi.org/10.18280/i2m.190405

Received: 3 October 2019

Accepted: 10 March 2020

\section{Keywords:}

fault diagnosis, fuzzy sliding mode observer, LMI, solar power plant, Takagi-Sugeno

\begin{abstract}
This article deals with the designing of fuzzy sliding mode observer in order to fault diagnosis in solar power plant. Purpose technique enable to the modulated using TakagiSugeno (TS) fuzzy models. Principal of proposed observer is to uses for estimate the state vector of the system; a Linear Matrix Inequalities (LMIs) is performed to ensure stability conditions. Foremother, it is deriving a diagnosis signal-residual. The residual is generated by the comparison of measured and estimated output. Proposed approach performance is tested in solar power plant model through numerical results.
\end{abstract}

\section{INTRODUCTION}

Exhaustive use of fossil-fuel-based traditional energy has reduced them and increased global warming, leading to the search for alternative resources. It is possible to achieve this by relying on renewable energies [1].

Solar power is the most important source on a farm that has been recognized as an exponential growth in recent years, from which many commercial solar power plants have been built [2].

For example, it is referred that as a development of three plants Andasol (50 MW) by Solar Millennium and located in southern Spain [3], Solana $280 \mathrm{MW}$ in Arizona [2] and Shams1 station (100 MW) in Abu Dhabi. The facility discussed in this paper is a 30 MW SEGS VI plant, which was established in 1988 by Luz International Ltd, which is located in the Mojave Desert in southern California [4].

Failures can occur in various instruments which can have a significant impact on the performance of the installation. So it is requiring monitoring and the fault diagnosis strategy improves productivity and increases their efficiency and reliability [5].

In the last years, many algorithms have been applied for the control of thermal solar power plants $[4,6,7]$ but the FDD algorithms are poor. FDI methods divided into two areas: data analysis methods the most widely used and widely used statistical techniques for industrial process monitoring and multivariate methods based on artificial intelligence [5, 8-10]; model based on linear observers, nonlinear, in sliding mode and the Kalman filter [11-14]. The concept of IDEs using these methods is done in two steps. The first is the generation of fault indicators by calculating the difference between the actual states of the system and their estimates and the second identifying the defects. Obviously, they need the precise mathematical model of the system. Generally, nonlinear systems are first linearized around an operating point. Then robust techniques are applied to manage the residuals that must be insensitive to modeling errors.

Solar plants are represented by nonlinear differential equations [12]. LTE form alone is not accepted, then we encounter the multi model ref approach. This consists of a collection of linear systems interconnected by non-linear functions. Several categories of multi-models exist in the literature, notably the Linear Systems with Parameters Variant in time (LPV) [15] or the quasi LPV, also called TakagiSugeno (TS) systems [16]. Let us note that the latter possess a property of universal approximation of the affine systems in the command and have the advantage of being able to accurately represent a model of nonlinear knowledge on a compact of the state space [16]. Thus, the major interest of this type of approach is that it allows to extend many theoretical concepts of the linear automaton to the case of nonlinear systems.

Recently, several researches have exploited the fuzzy modeling approach for the detection and the isolation of faults [17], Gao et al. [18], have proposed an alternative approach to the reconstruction of sensor faults using fuzzy observer TS based on an increased blurred descriptor system $[\mathrm{x}]$, these observers are not robust. To achieve robustness, TS observers blurred were combined with the sliding mode [19] called TSSMO can treat several faults and limited uncertainties in a well-defined theoretical framework, including the estimation of faults and the possible reconstruction of unknown inputs [17].

In this article, a methodology for diagnosing solar power plants described by T-S models using sliding mode observers is proposed. In general, the design of a fuzzy observer requires a precise mathematical description of the installation (proposed by Stuetzle [4] in the form of a dynamic model, which includes both local linear models and data logic functions activation. Local linear models are affine models of space state that can be derived directly from the first principle or empirical models. The paper is structured as follows: Section 2 presents the description of the components of the solar power plant. A TS model is presented in Section 3. A TSSMO and a fault detection method using the equivalent output injection signal in combination with operating phase detection is developed in Section 4. A simulation study is presented in 
section 5, where the demonstration of the robustness and the effectiveness of the proposed FDI scheme are confirmed. At the last, a conclusion and some remarks are affirmed.

\section{PLANT DESCRIPTION}

Solar Energy Generating System (SEGS) is a thermodynamic solar power plant with parabolic mirrors. The parabolic troughs are long parallel rows of curved glass mirrors focusing the sun's energy and are directed to a central tube filled with synthetic oil. Proposed solar power plant is a combination of two parts: the solar collector field and the power plant ("30 MW SEGS VI Plant" by SANDIA) [4]. The solar power plant can be present in a simplified model as viewing in Figure 1 consisting of four basic components: a solar collector, an expansion vessel, a heat exchanger and an HTF pump. Each element expresses its temperature change with a nonlinear differential equation, this model is used to design a quasi-LPV model. For a detailed description of the plant and a full description of the modelling procedure you can consult [4].

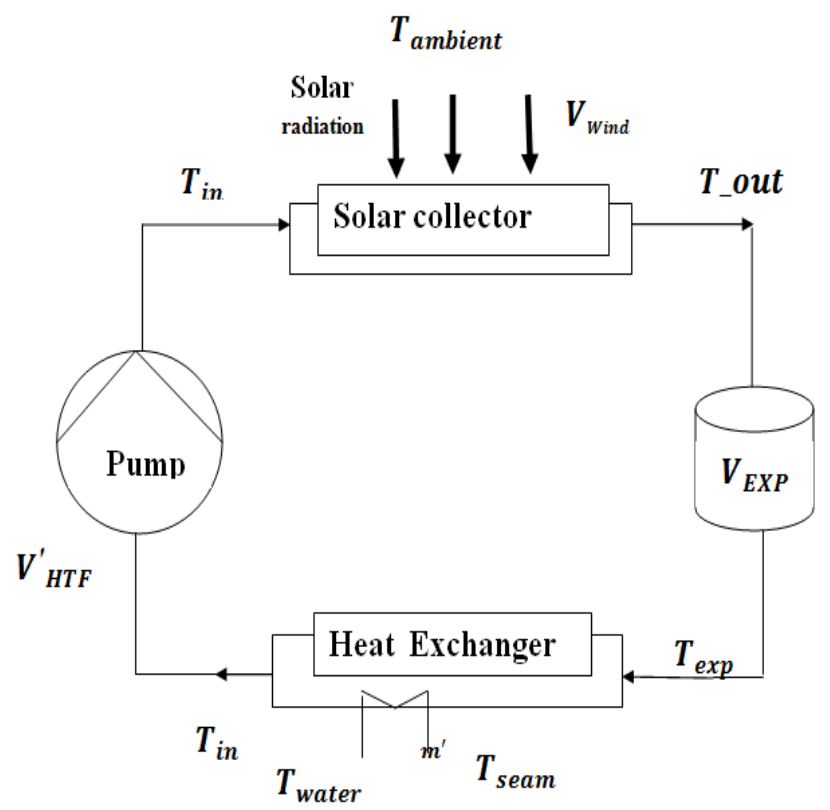

Figure 1. The structure of the simplified model

Dynamic model of the plant is described by four nonlinear differentials equations as illustrates flowing:

$$
\begin{array}{r}
\frac{d T_{\text {out }}(t)}{d t}=\frac{1}{\tau_{\text {col }}(t)}\left(T_{\text {in }}(t)-T_{\text {out }}(t)\right) \\
+\frac{Q_{\text {absorbed }}-U A_{\text {col }}\left(T_{\text {out }}(t)-T_{\text {amb }}(t)\right)}{A_{\text {col }} \rho_{H T F}\left(T_{\text {out }}(t)\right) c_{H T F}\left(T_{\text {out }}(t)\right)} \\
\frac{d T_{\operatorname{Exp}}(t)}{d t}=\frac{1}{\tau_{\text {Exp }}(t)}\left(T_{\text {out }}(t)-T_{\text {Exp }}(t)\right)
\end{array}
$$

$$
\begin{aligned}
& \frac{d T_{\text {in }}(t)}{d t} \\
& =\frac{1}{\tau_{H E}(t)}\left(T_{E x p}(t)-T_{\text {in }}(t)\right) \\
& +\frac{U A_{H E}\left(T_{\text {Exp }}(t)+T_{\text {in }}(t)-T_{\text {steam }}(t)-T_{\text {water }}(t)\right)}{A_{\text {col }} \rho_{\text {HTF }}\left(T_{\text {out }}(t)\right) c_{\text {HTF }}\left(T_{\text {out }}(t)\right)}
\end{aligned}
$$

$$
\begin{aligned}
& \frac{d T_{\text {steam }}(t)}{d t}=0.01 .\left(\left(-T_{\text {steam }}\right)\right. \\
& \quad-\varepsilon_{H E}(t)\left(T_{\text {Exp }}(t)-T_{\text {water }}(t)\right) \\
& \left.\quad-T_{\text {water }}(t)\right)
\end{aligned}
$$

The parameters of the model and their units are given in Table 1 . The density $\rho_{H T F}$ and the specific heat capacity $C_{H T F}$ depend on the temperature of the fluid, the heat transfer coefficients $\varepsilon_{H E}, h_{H E}$ depend on the on the flow rate. The reference flow rates are $\dot{V}_{H T F, 0}=0.624 \mathrm{~m}^{3} \mathrm{~s}^{-1}$ for the HTF volume flow rate and $\dot{m}_{0}=39.9 \mathrm{kgs}^{-1}$ for the mass flow rate of the working fluid.

\section{DYNAMIC MODEL AND (T-S) FUZZY MODEL REPRESENTATION OF SOLAR POWER PLANT}

\subsection{The state space model}

Based on (1), (2), (3) and (4) and, for a comparison with the time-invariant linear state-space model:

$$
\left\{\begin{array}{c}
\dot{x}(t)=A(x) \cdot x(t)+B u(t) \\
y(t)=C x(t)
\end{array}\right.
$$

We obtain:

$$
\left[\begin{array}{c}
\mathrm{T}_{\text {out }} \cdot(\mathrm{t}) \\
\mathrm{T}_{\text {exp }} \cdot(\mathrm{t}) \\
\mathrm{T}_{\text {in }} \cdot(\mathrm{t}) \\
\mathrm{T}_{\text {st }} \cdot(\mathrm{t})
\end{array}\right]=\mathrm{A}(\mathrm{x})\left[\begin{array}{c}
\mathrm{T}_{\text {out }}(\mathrm{t}) \\
\mathrm{T}_{\exp }(\mathrm{t}) \\
\mathrm{T}_{\text {in }}(\mathrm{t}) \\
\mathrm{T}_{\text {st }}(\mathrm{t})
\end{array}\right]+\mathrm{B}(\mathrm{x})\left[\begin{array}{c}
\dot{\mathrm{V}}_{\mathrm{HTF}}(\mathrm{t}) \\
\mathrm{Q}_{\mathrm{abs}}(\mathrm{t}) \\
\mathrm{T}_{\text {amb }}(\mathrm{t}) \\
\dot{\mathrm{m}}_{\mathrm{HTF}}(\mathrm{t}) \\
\mathrm{T}_{\text {water }}(\mathrm{t})
\end{array}\right]
$$

where, $A(x)$ is the system matrix and $B(x)$ is the disturbance matrix.

The state vector is defined below:

$$
x(t)=\left[T_{\text {out }}(t) T_{\text {exp }}(t) T_{\text {in }}(t) T_{\text {steam }}(t)\right]^{T} .
$$

The input vector is defined below:

$$
=\left[\begin{array}{c}
\mathrm{u}(\mathrm{t}) \\
\left.\dot{\mathrm{V}}_{\mathrm{HTF}}(\mathrm{t}) \mathrm{Q}_{\mathrm{abs}}(\mathrm{t}) \mathrm{T}_{\mathrm{amb}}(\mathrm{t}) \dot{\mathrm{m}}_{\mathrm{HTF}}(\mathrm{t}) \mathrm{T}_{\text {water }}(\mathrm{t})\right]^{\mathrm{T}}
\end{array}\right.
$$

However, a slight variation is used here cannot considered to be manipulated for the purpose of the collector outlet temperature control (as the steam mass flow rate $\dot{\boldsymbol{m}}_{\boldsymbol{H} \boldsymbol{T} \boldsymbol{F}}(\boldsymbol{t})$ in this study). In order to control the collector outlet temperature, only the HTF volume flow rate $\dot{\boldsymbol{V}}_{\boldsymbol{H T F}}(\boldsymbol{t})$ is adjusted using: $U_{m}(t)=\dot{V}_{H T F}(t)$. The input variable $\boldsymbol{U}_{\boldsymbol{m}}(\boldsymbol{t})$ stands for manipulable input and vector of non-manipulated inputs is defined as:

$$
\mathrm{u}_{\mathrm{d}}(\mathrm{t})=\left[\mathrm{Q}_{\mathrm{abs}}(\mathrm{t}) \mathrm{T}_{\mathrm{amb}}(\mathrm{t}) \dot{\mathrm{m}}_{\mathrm{HTF}}(\mathrm{t}) \mathrm{T}_{\text {water }}(\mathrm{t})\right]^{\mathrm{T}}
$$

According to the space model, it finds that the matrix system $\mathrm{A}(\mathrm{x})$ and the disturbance matrix $\mathrm{B}$ are not fixed matrices.

\subsection{Procedure for obtaining the Takagi-Sugeno (T-S) fuzzy model representation}

The use of fuzzy logic theory is a natural tool that increases 
the performance of control and supervision and especially for systems characterized by incomplete information and noise. Thus, fuzzy logic techniques are now widely used as a powerful tool for modeling and decision support. This approach is a mathematical alternative to represent, in order to be able to analyze, a nonlinear system by means of a set of simple structural models, each valid in a partition of the operating space of the system. Local models are then grouped together using an interpolation mechanism. LPV models describe how the dynamics of the system vary according to one or more variable planning parameters. When the variation of the scheduling parameters depends on the state space variables and / or the input variables, they are referred to as T$\mathrm{S}$ fuzzy model. The use of this approach makes it possible to transfer and generalize several methods developed in the field of linear monitoring to nonlinear systems and gives good approximation properties that can be used for monitoring.

T-S fuzzy model obtained is given following:

$$
\left\{\begin{array}{l}
\dot{x}(t)=A(\xi) x(t)+B(\xi) u(t) \\
y(t)=C(\xi) x(t)+D(\xi) u(t)
\end{array}\right.
$$

The Quasi-LPV model is derived according to three scheduling variables

$$
\begin{gathered}
\xi_{1}(\mathrm{t})=\dot{\mathrm{V}}(\mathrm{t}) . \\
\xi_{2}(\mathrm{t})=-0.1\left(\dot{\mathrm{V}} / 2 \cdot \mathrm{V}_{0}+\frac{\dot{\mathrm{m}}(\mathrm{t})}{\cdot} \mathrm{m}_{0}\right)+1.025 \\
\xi_{3}(\mathrm{t})=\mathrm{T}_{\operatorname{Exp}}(\mathrm{t})
\end{gathered}
$$

These scheduling variables in SPP are assumed to vary within the operating range. Notice that several choices of these premise variables are possible, due to the existence of different equivalent Quasi-LPV forms.

The system (1) ... (4) can be rewritten as:

$$
\dot{x}=A(\xi(t)) x(t)+B_{m}(\xi(t)) u_{m}(t)+B_{d}(\xi(t)) u_{d}(t)
$$

where, $\xi(t)=\left[\xi_{1}(t) \xi_{2}(t) \xi_{2}(t)\right]^{\mathrm{T}}$ and the matrices $A(\xi(t)), B_{m}(\xi(t))$ and $B_{d}(\xi(t))$ are expressed as follows:

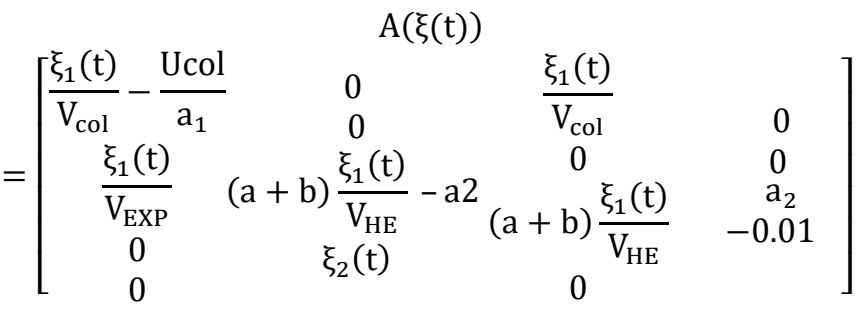

$$
\begin{aligned}
& \mathrm{B}_{\mathrm{m}}(\xi(\mathrm{t}))=\left[\begin{array}{c}
0 \\
\frac{\xi_{3}(\mathrm{t})}{\mathrm{V}_{\text {EXP }}} \\
\xi_{3}(\mathrm{t}) \\
\frac{\mathrm{V}_{\text {EXP }}}{0}
\end{array}\right] ; \mathrm{B}_{\mathrm{d}}\left(\xi(\mathrm{t})=\left[\begin{array}{cccc}
\frac{1}{\mathrm{a}_{1}} & \frac{\mathrm{u}_{\text {Acol }}}{\mathrm{a}_{2}} & 0 & 0 \\
0 & 0 & 0 & 0 \\
0 & 0 & 0 & \mathrm{a}_{2} \\
0 & 0 & 0 & \xi_{2}(\mathrm{t})
\end{array}\right]\right.
\end{aligned}
$$

where,

$$
\begin{gathered}
a_{1}=A_{\text {col }} \cdot \rho_{H T F}\left(T_{\text {out }}\right) \cdot C_{H T F} \\
a_{2}=\frac{U A_{H E}}{2 \cdot A_{H E} \rho_{H T F}(\text { Tin }) C_{H T F}(\text { Tin })} \\
\mathrm{a}=\mathrm{b}=0.4375 .
\end{gathered}
$$

The set of $r=8$ local models can be computed by taking $\vartheta_{j, i}$, for $j=1 \sim 3$ and $i=1 \sim 8$.

$\mathrm{D}$ as the minimum or maximum value for decision variable $\xi_{i}$ with: $d_{1} \leq \xi_{1} \leq D_{1}, d_{2} \leq \xi_{2} \leq D_{2} ; d_{3} \leq \xi_{3} \leq D_{3}$, respectively.

And the local weighting functions defined by:

$$
w_{j}^{1}(\xi)=\frac{D_{j}-\xi_{j}(t)}{D_{j}-d_{j}}, w_{j}^{2}(\xi)=\frac{\xi_{j}(t)-d_{j}}{D_{j}-d_{j}} \cdot j=1 \sim 3
$$

The weighting functions of the derived T-S model and the matrices $A_{i} B_{i} C$ are given in Table 1:

Table 1. The local models

\begin{tabular}{c|c|c|c}
\hline Model & $\xi_{1 j} \xi_{2} \xi_{3}$ & Matrices & weighting functions \\
\hline 1 & $D_{1} D_{2} D_{3}$ & $A_{1} B_{1} C$ & $\mu_{1}=w_{1}^{1} w_{2}^{1} w_{3}^{1}$ \\
2 & $D_{1} D_{2} D d_{3}$ & $A_{2} B_{2} C$ & $\mu_{2}=w_{1}^{1} w_{2}^{1} w_{3}^{2}$ \\
3 & $D_{1} d_{2} D_{3}$ & $A_{3} B_{3} C$ & $\mu_{3}=w_{1}^{1} w_{2}^{2} w_{3}^{1}$ \\
4 & $D_{1} d_{2} d_{3}$ & $A_{4} B 4 C$ & $\mu_{4}=w_{1}^{1} w_{2}^{2} w_{3}^{2}$ \\
5 & $d_{1} D_{2} D_{3}$ & $A_{5} B_{5} C$ & $\mu_{5}=w_{1}^{2} w_{2}^{1} w_{3}^{1}$ \\
6 & $d_{1} D_{2} d_{3}$ & $A_{6} B_{6} C$ & $\mu_{6}=w_{1}^{2} w_{2}^{1} w_{3}^{2}$ \\
7 & $d_{1} d_{2} D_{3}$ & $A_{7} B_{7} C$ & $\mu_{7}=w_{1}^{2} w_{2}^{2} w_{3}^{1}$ \\
8 & $d_{1} d_{2} d_{3}$ & $A_{8} B_{8} C$ & $\mu_{8}=w_{1}^{2} w_{2}^{2} w_{3}^{2}$ \\
\hline
\end{tabular}

Consequently, the nonlinear model (1-4) can be proposed as:

$$
\left\{\begin{array}{c}
\dot{x}(t)=\sum_{i=1}^{8} \mu_{i}(\xi(t))\left(A_{i} x(t)+B_{m_{i}} u_{m}(t)+B_{d_{i}} u_{d}(t)\right) \\
y(t)=C x(t)
\end{array}\right.
$$

\section{FUZZY SLIDING MODE OBSERVER}

Different faults and failures can occur in SPP instruments, equipment and systems which can have a significant impact on the performance and productivity of the installation. The design of the thermal measurement system for the detection of faults in a power generation system improves the productivity of the SPPs [20]. The monitoring of this SPP modeled as a state then consists in studying the behavioral coherence of the model ender real system. Sliding observers are known for their robustness and insensitivity to many types of uncertainty. These observers are more robust than the Luenberger observers, since the discontinuous term allows observers to reject disturbances and are also independent of a class of discordance between the system and the observer. Yan and Edwards [21] proposed an observer for actuator defect detection similar to that proposed by Bergsten et al. [22]. for a class of nonlinear systems. However, sensor fault detection is not expected. Therefore, this approach is not sufficient to guarantee the safety of Tanaka and Wang [16]. However, this observer is not robust and fault detection and identification (FDI) is not considered. To improve performances, an alternative approach to observer based sensor fault reconstruction using a TS fuzzy observer based on an augmented fuzzy descriptor system has been proposed by Gao et al. [18]. In the same objective, TS fuzzy observers have been combined with sliding mode in many researches where the more important are cited by Gao et al. [18]. Two TS-SM observers have been proposed by Bergsten [22] and the drawback is the application to FDI is not considered. Edwards and Spurgeon [23] proposed residuals of a bank of TS-SM observers are evaluated for FDI. Theory and application is presented following. 
Assume that the fuzzy approximation of a nonlinear system reads:

$$
\left\{\begin{array}{c}
\dot{x}=\sum_{i=1}^{M} \mu_{i}(\xi)\left(A_{i} x+B_{i} u\right)+f(t, x, u) \\
y=C . x
\end{array}\right.
$$

And the following assumptions are satisfied:

$$
\begin{gathered}
A_{1} \cdot f(t, x, u)=R \bar{u}(t) \\
A_{2} \cdot R=\sum_{\substack{i=1 \\
M}}^{M} \mu_{i}(\xi) \cdot R_{i} \\
A_{3} \cdot \bar{u}(t) \in R^{q}, R_{i} \in R^{n \times q} \text {, and } C \in R^{p \times n} \text { with } p \geq q .
\end{gathered}
$$

The proposed observer for the multiple models (15) is a linear combination of local observers, each of them having the structure proposed by Walcott and Zak [24]. In this work, it considers that the inputs $\|\bar{u}(t)\| \leq \eta$, where is scalar and \|\| represents the Euclidean norm.

The proposed sliding mode fuzzy observer of the T-S model has presented on the following form:

$$
\left\{\begin{array}{c}
\dot{\hat{x}}=\sum_{i=1}^{M} \mu_{i}(\xi)\left(A_{i} \hat{x}+B_{i} u+G_{i} e_{y}+R_{i} V_{i}+\alpha_{i}\right) \\
y=C \hat{x}
\end{array}\right.
$$

where, $e_{y}$ is output error. It is defined on the following form

$$
e_{y}=y-\hat{y}=C(x-\hat{x})=\operatorname{Ce}(t)
$$

With $e(t)$ represent the state estimation error, such as:

$$
e(t)=x(t)-\hat{x}(t)
$$

The matrices $G_{i}$ and the control variables $V_{i}$, with $V_{i}(t) \in R^{t}$ must be determined in order to guarantee the asymptotic convergence of $\hat{x}(t)$ towards $x(t)$.

The terms $V_{i}(t)$ compensate errors due to the unknown inputs. The dynamic of state estimation error is given as follows:

$$
\left.\dot{e}=\sum_{i=1}^{M} \mu_{i}(\xi)\left(A_{i}-G_{i} C\right) e+R_{i} \bar{u}-R_{i} V_{i}\right)
$$

The matrices $G_{i}$ and the control variables $V_{i}$, with $V_{i}(t) \in$ $R^{t}$ must be determined in order to guarantee the asymptotic convergence of $\hat{x}(t)$ to wards $x(t)$. The terms $V_{i}(t)$ compensate errors due to the unknown inputs. The dynamic of state estimation error is given as following:

$$
\text { If } \mathrm{r}_{\mathrm{y}} \neq 0\left\{\begin{array}{c}
\mathcal{V}_{\mathrm{i}}=\rho^{2} \beta_{3}^{-1} \frac{\left\|P R_{\mathrm{i}}\right\|^{2}}{2 \mathrm{r}_{\mathrm{y}}^{\mathrm{T}} \mathrm{r}_{\mathrm{y}}} \mathrm{P}^{-1} \sum_{\mathrm{j}=1}^{\mathrm{M}} \mu_{\mathrm{i}}(\xi) \mathrm{C}_{\mathrm{j}}^{\mathrm{T}} \mathrm{r}_{\mathrm{y}} \\
\alpha_{\mathrm{i}}=\beta_{1}\left(1+\beta_{2}\right) \delta_{\mathrm{i}}^{2} \frac{\hat{\mathrm{x}}^{\mathrm{T}} \hat{\mathrm{x}}}{2 \mathrm{r}_{\mathrm{y}}^{\mathrm{T}} \mathrm{r}_{\mathrm{y}} \mathrm{P}^{-1} \sum_{\mathrm{j}=1}^{\mathrm{M}} \mu_{\mathrm{i}}(\xi) \mathrm{C}_{\mathrm{j}}^{\mathrm{T}} \mathrm{r}_{\mathrm{y}}} \\
\text { If } \mathrm{r}_{\mathrm{y}}=0 \quad\left\{\begin{array}{l}
\mathcal{V}_{\mathrm{i}}=0 \\
\alpha_{\mathrm{i}}=0
\end{array}\right.
\end{array}\right.
$$

\section{SIMULATION}

There are many faults as classify:
- Defect in steam turbines for example, bearing temperature sensor fault, leakage fault in the lubricating oil circuit and proximity sensor fault in shaft axial position. These defects reduce the efficiency of the steam turbines, thus reducing the overall efficiency of the SPP. A dangerous situation can occur.

- Actuator or leakage faults occur in the absorber pipe witch pumped the heat fluid to the boiler Impact on the reduced combustion efficiency and then the insufficient amount of superheated rods of the turbine.

- Faults in the control of boiler feed water, for example, a fault in the actuator that pumps water into the boiler and the sensor passes during the change of load, which affects the safety and the efficiency of the boiler.

The direct measures available from the plant are the outlet and the inlet oil temperature, expansion vessel and the heat exchanger temperature and the solar radiation. An observer is needed to estimate the intermediate temperatures of the plant for the model described in section 2. Since the process is described by four non linear PDE, a Proposed T-S model that described in section 3 is formed by eight 'IF-THEN' logical rules. It has a fuzzy antecedent part and a functional consequent part. Concerning the dynamics of the solar power plant and its nonlinear model structure, three fuzzy variables are considered in the antecedent part of the T-S model.

The local dynamic models are deduced from the nonlinear model $(1, ., 4)$ through dynamic linearization by sector transformation.

\subsection{Estimation state}

In order to validate the performance of the proposed observer, simulation test is realized and obtain results are presented in Figures 2 and 3 respectively.

Figure 2 shows the unknown inputs presented to the system while Figure 3 shows the state estimation. Based on these figures, it can be seen that the observer performs as expected despite the presence of the unknown input and the real and estimated states are found to be close.

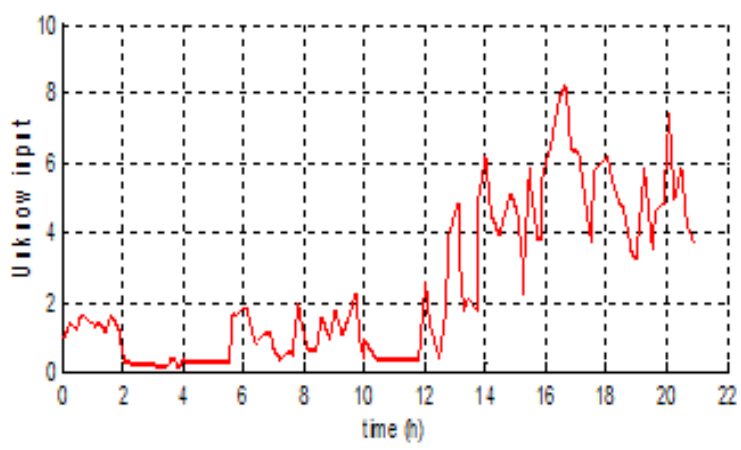

Figure 2. The unknown input

\subsection{Fault detection and isolation for SPP model (sensor faults)}

In order to identify the sensor fault, we consider that the Actuator is faultless $(\bar{u}=0)$ while the output vector $\mathrm{y}$ is corrupted by the sensor fault $\Delta y=0$. Proposed observer (21) is designed to estimate the output of the system and generate the diagnostic signal-residual that indicates whether or not a fault appears. In this work, three fuzzy sliding mode observers are used, one based on the outlet collector temperature observer: 
$y_{1}=T_{\text {out }}\left(f_{1}\right)$, the second based on the expansion temperature $y_{2}=T_{\exp }\left(f_{2}\right)$ and the last is based on the steam temperature $y_{3}=T_{\text {steam }}\left(f_{3}\right)$. The structured residual is designed to be sensitive to a certain group of faults and insensitive to others. The sensitivity and insensitivity properties make the faults isolation possible. The ideal situation is to make each residual sensitive only to a particular fault and insensitive to all others. For example, system is sensitive to certain faults $\left(f_{1}, f_{2}, f_{3}\right)$ which cause that the diagnostic signal-residual to be active or not. This response pattern is known as fault signature. For the SPP, the response pattern is done by Table 2 . It observes that a fault in sensor 1 will only activate the residual 1 , and a fault in sensor 2 will activate the residuals 2, fault in sensor 3 will activate the residuals 3 .
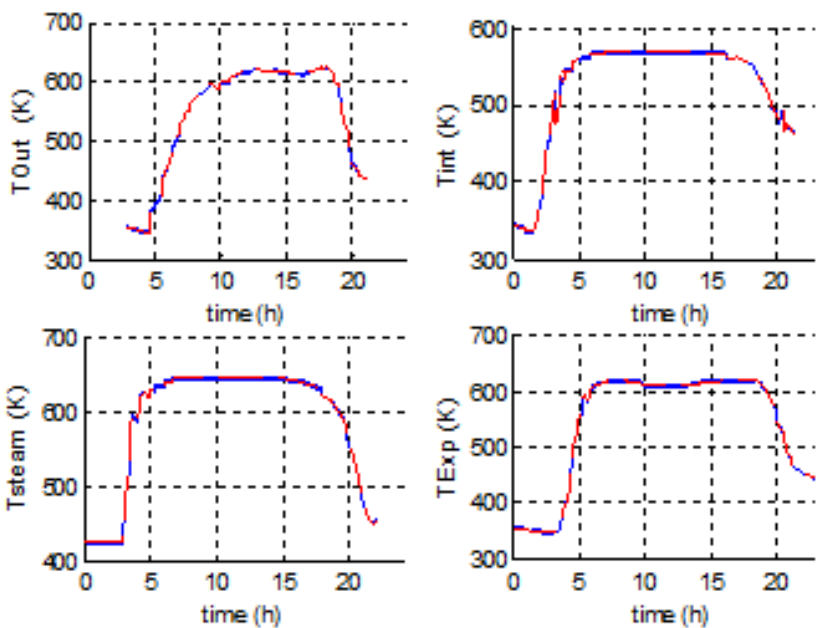

Figure 3. The four states: Dotted line: estimated state; solid line: real state

Table 2. Fault signatures

\begin{tabular}{ccccc}
\hline \multicolumn{5}{c}{ Faults } \\
\hline Residual & $f_{1}$ & $f_{2}$ & $f_{3}$ & Notes \\
R1 & 1 & 0 & 0 & $f_{1}$ : fault in sensor1 \\
R2 & 0 & 1 & 0 & $f_{2}$ : fault in sensor2 \\
R3 & 0 & 0 & 1 & $f_{3}:$ fault in sensor3 \\
\hline
\end{tabular}

Based on TS fuzzy model and proposed fuzzy observer designing, the following three cases have been simulated.

Case 1: Fault-free system:

Figure 4 shows the response of the residuals for this case. It seen that residuals have not been activated, as expected, indicating that the system is indeed free of faults.

Case 2: System with faults.

Scenario 1: residual signals 1, 2 and 3 behaviors are illustrated by Figure 5 when a sudden decrease of $10 \%$ gain is occurs at time [90-120]. It is predicted by the fault signature matrix, only the residual 1 (r1) is activated therefore we can assume that the fault appears only in the outlet temperature sensor.

Scenario 2: an abrupt fault is introduced in sensor 1 at time [60-90] and in sensor 3 at time [130-160]. In the same way simultaneous faults in sensors have been simulated. Figure 6 shows the estimation of sensor faults $\hat{f}_{1}$ and $\widehat{f}_{3}$.
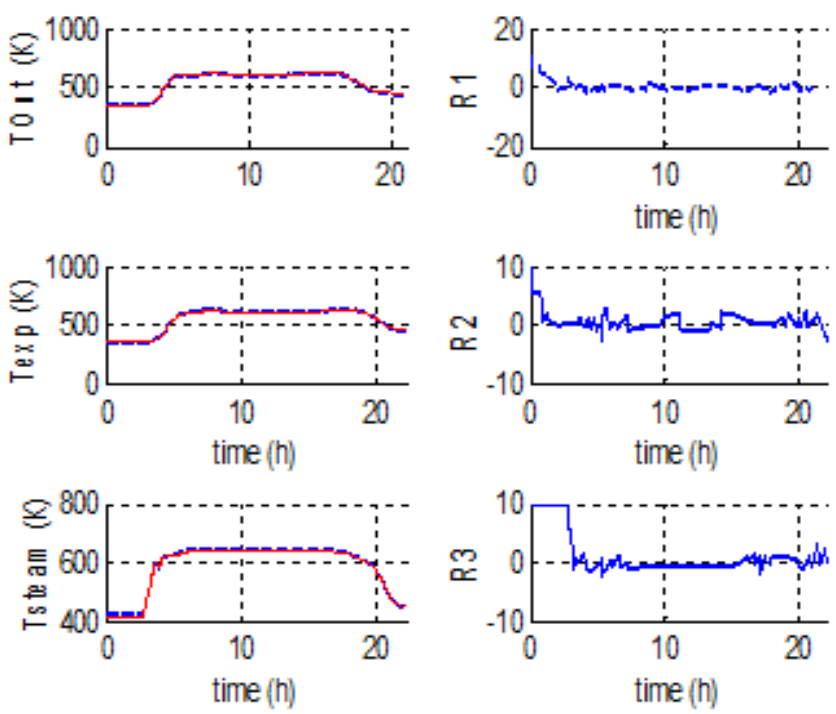

Figure 4. Residuals for a fault-free system
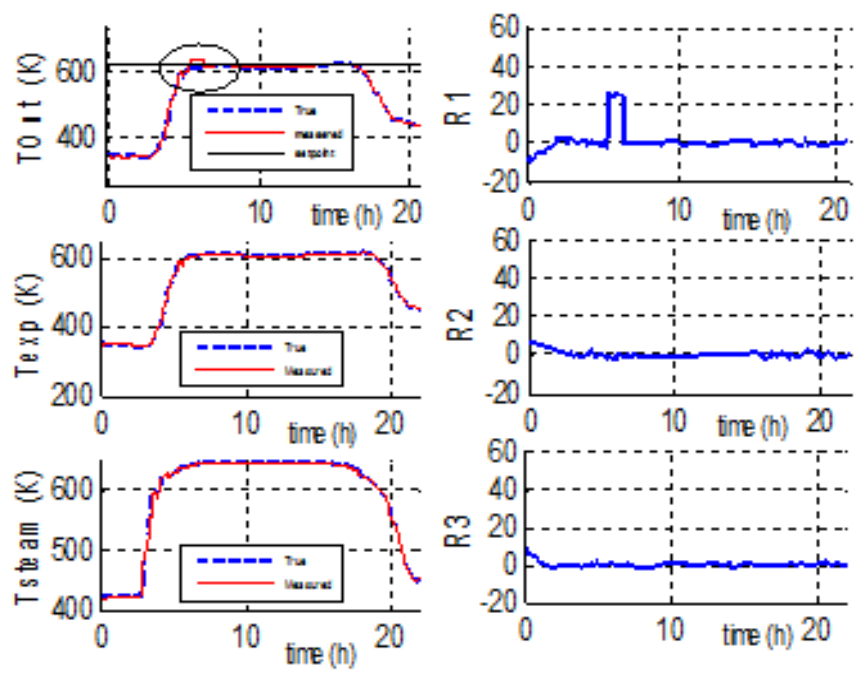

Figure 5. Comparison between true and measured outlet collector temperature in presence of fault in temperature measurement (Residuals corresponding to a fault in sensor 1)
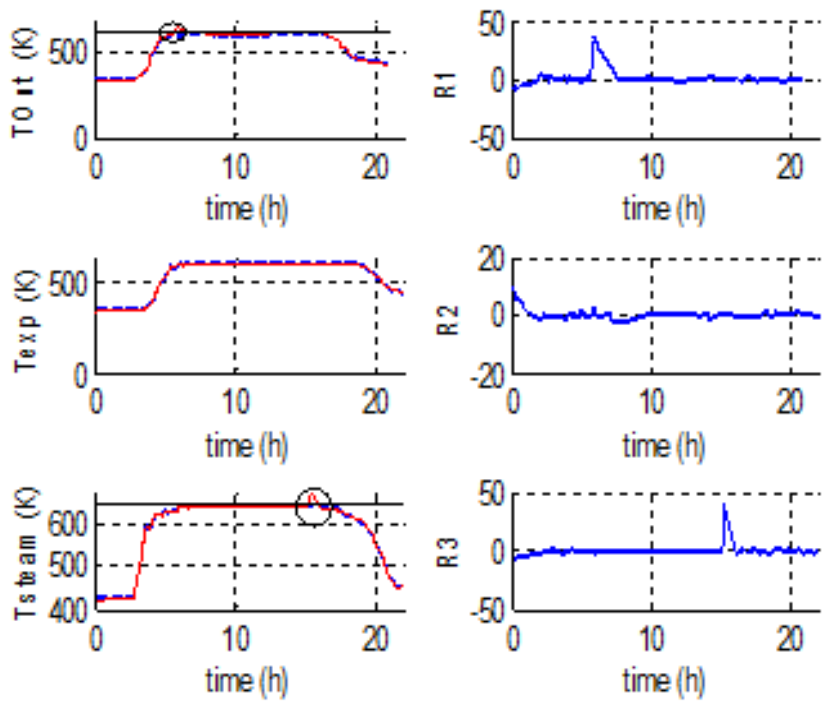

Figure 6. Residuals corresponding to a fault in sensor 1 and 3 


\section{CONCLUSIONS}

This work has successfully developing of a sliding mode observer based on Takagi-Sugeno fuzzy model for detection fault in solar power plant application. After developing a reasonable model based on Takagi-Sugeno fuzzy type, the system was tested for many faults conditions. Furthermore, an approach for fuzzy adapting failure thresholds was proposed. Results were obtained using MATLAB proving that the proposed procedure of fault detection in the solar plant was provide an effectiveness and height robustness that enable to establish more fault diagnosis performance. Finally, result of this work opens a new way of researches in this array.

\section{ACKNOWLEDGMENT}

The authors would like to gratefully acknowledge the laboratory of Automatic and Signals Annaba (LASA); Badji Mokhtar University, P.Q.Box 12 , Annaba 23000,Algeria.

\section{REFERENCES}

[1] Chabane, F., Moummi, N., Brima, A. (2018). Experimental study of thermal efficiency of a solar air heater with an irregularity element on absorber plate. International Journal of Heat and Technology, 16(14): 1264-1277.

http://doi.org/10.1080/15435075.2019.1671401

[2] Geyer, M.A., Aringhoff, R., Herrmann, U., Kistner, R., Nava, P., Osuna, R. (2002). AndaSol: 50MW solar plants with 9 hour storage for southern Spain. 11th SolarPACES International Symposium on Concentrated Solar Power and Chemical Energy Technologies, Zurich, Switzerland.

https://www.researchgate.net/publication/298957750_A ndaSol_50MW_Solar_Plants_with_9_Hour_Storage_fo r_Southern_Spain.

[3] Blaise, K.K.K., Magloire, K.E.P., Prosper, G. (2018). Thermal performance amelioration of flat plate solar collector of an indirect dryer. Mathematical Modelling of Engineering Problems, 5(4): 341-347. https://doi.org/10.18280/mmep.050410

[4] Stuetzle, T., Blair, N. (2001). Automatic control of a 30 MWe SEGS VI parabolic trough plant. ISES Solar World Congress http://doi.org/10.1016/J.silener.2003.01.002

[5] Garcia, R.F., Calvo Rolle, J.L., Castelo, J.P., Gomez, M.R. (2014). On the monitoring task of solar thermal fluid transfer systems using NN based models and rule based. techniques. Engineering Applications of Artificial Intelligence, 27: https://doi.org/10.1016/j.engappai.2013.06.011

[6] Gallego, A.J., Fele, F., Camacho, E.F. (2013). Observerbased model predictive control of a parabolic-trough field. Solar Energy, 97: 426-435. https://doi.org/10.1016/j.solener.2013.09.002

[7] Lu, X.J., Dong, H.Y. (2017). Application of multi-model active fault-tolerant sliding mode predictive control in solar thermal power generation system. Acta Automatica Sinica, 43(7): 1241-1247. https://doi.org/10.16383/j.aas.2017.e150319

[8] Berenguel, M., Klempous, R., Maciejewski, H., Nikodem, J., Nikodem, M., Valenzuela, L. (2005). Data analysis of a distributed solar collector field. 10th International Workshop on Computer Aided Systems Theory, Las Palmas de Gran Canaria, Spain. http://dx.doi.org/10.1007/11556985_83

[9] Ajami, A., Daneshvar, M. (2012). Data driven approach for fault detection and diagnosis of the turbine in a thermal power plant using Independent Component Analysis (ICA). International Journal of Electrical Power \& Energy Systems, 43(1): 728-735. http://doi.org/10.1016/j.ijepes.2012.06.022

[10] Arian, D., Benyamin, K., Isti, S. (2017). Neural network based system for detecting and diagnosing faults in the steam turbine of the thermal power plant. 2017 IEEE 8th International Conference on Awareness Science and Technology (iCAST), Taichung, Taiwan. http://doi.org/10.1109/ICAwST.2017.8256435

[11] Roubache, T., Chaouch, S., NaïtSaïd, M.S. (2018). Comparative study between luenberger observer and extended kalman filter for fault-tolerant control of induction motor drives. Advances in Modelling and Analysis $\quad$ C, $\quad 73(2)$ : 29-36. https://doi.org/10.18280/ama_c.730201

[12] Taif, Z., Lafifi, M.M., Boulebtateche, B. (2014). Diagnosis of a solar power plant using TS fuzzy-based multimodel approach. 16th International Power Electronics and Motion Control Conference and Exposition (2014), Antalya, Turkey. http://doi.org/10.1109/EPEPEMC.2014.6980513

[13] Patton, R.J., Chen, J. (1997). Observer-based fault detection and isolation: robustness and applications. Control Engineering Practice, 5(5): 671-682. http://doi.org/10.1016/S0967-0661(97)00049-X

[14] Chen, J., Patton, R.J. (1999). Robust Model-Based Fault Diagnosis for Dynamic Systems. Kluwer Academic Publishers, 777-780.

[15] Wang, J.H., Gao, Y., Qiu, J., Ki Ahn, C. (2016). Sliding mode control for non-linear systems by Takagi-Sugeno fuzzy model and delta operator approaches. IET Control Theory \& Applications, 11(8): 1205. http://dx.doi.org/10.1049/iet-cta.2016.0231

[16] Tanaka, K., Wang, H.O. (2001). Fuzzy Control Systems Design and Analysis: A Linear Matrix Inequality Approach. J. Wiley\& Sons.

[17] Ahlem, B., Fayçal, A., SaÏdi, M.L. (2018). Intelligent condition monitoring of variable speed wind energy conversion systems based on decentralized sliding mode observer. Advances in Modelling and Analysis C, 73(2): 37-44. http://doi.org/10.18280/ama-c.730202

[18] Gao, Z., Shi, X., Ding, S.X. (2008). Fuzzy state/disturbance observer design for TS fuzzy systems with application to sensor fault estimation. IEEE Transactions on Systems, 38(3): 875-880. https://doi.org/10.1109/TSMCB.2008.917185

[19] Edwards, C., Spurgeon, S.K., Patton, R.J. (2000). Sliding mode observers for fault detection and isolation. Automatica, 36(4): 541-553. https://doi.org/10.1016/S0005-1098(99)00177-6

[20] Chillar, R., Kauffman, E.J., Ansari, A. (2015). U.S. Patent No. 9,019,108. Washington, DC: U.S. Patent and Trademark Office. https://www.uspto.gov/aboutus/news-updates/patent-phonograph-issued-february19-1878-one-edisons-f irst-great-inventions.

[21] Yan, X.G., Edwards, C. (2007). Nonlinear robust fault reconstruction and estimation using a sliding mode 
observer. Automatica, 43(9): 1605-1614. https://doi.org/10.1016/j.automatica.2007.02.008

[22] Bergsten, P., Palm, R., Driankov, D. (2002). Observers for Takagi-Sugeno fuzzy systems. IEEE Transactions on Systems, Man, and Cybernetics, Part B: Cybernetics, 32(1): 114-121. https://doi.org/10.1109/3477.979966

[23] Edwards, C., Spurgeon, S.K. (1998). Sliding Mode Control: Theory and Applications. Taylor and Francis, London.

[24] Walcott, B., Zak, S.H. (1987). State observation of nonlinear uncertain dynamical systems. IEEE Transactions on Automatic Control, 32(2): 166-170. https://doi.org/10.1109/TAC.1987.1104530

\section{NOMENCLATURE}

Time (s)
$T_{\text {out }}$

$T_{\text {exp }}$

$T_{\text {in }}$

$T_{\text {steam }}$

$\rho_{H T F}$

$C_{H T F}$

$q_{a b s}$

$\varepsilon_{H E}$

$\left.1 / \tau_{\text {coll }} t\right)$

\section{Subscripts}

SPP

TS

SMO

LMI outlet collector temperature $\left[\mathrm{K},{ }^{\circ} \mathrm{C}\right]$ expansion vessel temperature $\left[\mathrm{K},{ }^{\circ} \mathrm{C}\right]$ inlet collector temperature $\left[\mathrm{K},{ }^{\circ} \mathrm{C}\right]$ heat exchanger temperature $\left[\mathrm{K},{ }^{\circ} \mathrm{C}\right]$ density of fluid flow rate $\left[\mathrm{kgm}^{3}\right]$ specific heat of fluid flow rate $\left[\mathrm{Jk}^{-1} \mathrm{~kg}^{-1}\right]$ the absorbed solar energy $\left[\mathrm{Wm}^{-2}\right]$ the heat exchanger effectiveness the time constant for the collector

\section{Solar power plant}

Takagi-Sugeno

Sliding mode observer

Linear Matrix Inequalitie 